\section{US private funder on indirect costs}

As vice-president of the James $S$. McDonnell Foundation (JSMF), I wish to clarify our position on the recovery of indirect research costs, which include overheads such as administration and building-maintenance costs (Nature 476, 385; 2011). You are correct in that the JSMF does not allow applicant institutions to include indirect costs as a component of budget requests; however, this should not be branded as a 'refusal' to fund indirect costs.

The JSMF, like many private foundations, considers it inappropriate for institutions to request indirect costs from private funders. In the United States, recovery of indirect costs by universities is negotiated with federal funding agencies because most US-funded research is done on university campuses.

It is unfortunate that a misunderstanding over the history and reasons for recovering indirect costs continues to strain relations between universities and private funders. A core mission of universities and education is the creation of new knowledge through research and scholarship. Grants from private funders such as the JSMF are helping universities to realize these goals; contrary to common belief, foundation grants are budgetrelieving, not budget-additive. Providing for indirect costs would be incompatible with this traditional relationship.

Susan M. Fitzpatrick James $S$. McDonnell Foundation, St. Louis, Missouri, USA.

susan@jsmf.org

\section{Improve China's sustainability targets}

China's national and local governments have defined various eco-indicators to promote sustainable development. Some revisions are needed to improve economic performance, environmental quality and social development.

The State Council, for example, has proposed national emissionreduction targets in its latest five-year plan (2011-15), for which the eco-indicator is a reduction in carbon dioxide emissions per unit of gross domestic product by $40-45 \%$ in 2020 relative to 2005 levels (see go.nature.com/4k3mqo). Others include circular-economy indicators released by the National Development and Reform Commission in 2007 to address the environmental degradation and resource scarcity associated with rapid economic development (H. Li et al. Energy 35, 4273-4281; 2010); national eco-industrial park indicators set up by the environment ministry in 2006 (Y. Geng et al. J. Ind.

Ecol. 13, 15-26; 2009); regional sustainable-development indicators brought in by the science ministry in 2009; and national environmental-living indicators put forward this year by the housing ministry.

Most of these indicators are relative. Given China's rapid economic development, a reduction in terms of ratiobased indicators may not mean a net reduction in emissions and consumption of materials or energy.

There is no provision in sustainable-development plans generally for prevention-oriented indicators that reduce - rather than support - recycling and reuse. However, curtailing the production of reusable waste materials by promoting such an indicator would disadvantage producers and consumers who would benefit more from reuseand-recycling indicators.

Autonomy and lack of standardization allow local government officials to cherrypick their achievements to collect political credits and encourage them to select indicators that cast them in a positive light.

Data collection on eco-indicators is complicated when it involves different agencies. Officials need to secure cooperation from other relevant government agencies to guarantee the validity and accuracy of such data.

Most eco-indicators are voluntary and can be pursued with different intentions. The relatively rich regions of eastern China have a genuine interest in improving resource efficiency and environmental performance. The poorer western regions are more likely simply to want to gain access to national financial subsidies. Geng Yong Institute of Applied Ecology, Chinese Academy of Sciences, Shenyang, China. gengyong@iae.ac.cn

\section{Flagging flora: help frombacteriocins?}

With regard to Martin Blaser's concerns about the collateral damage to commensal bacteria caused by overuse of broadspectrum antibiotics (Nature 476, 393-394; 2011), there are some potent alternatives in the pipeline.

Bacteriocins are peptide antimicrobials that could be harnessed to control a variety of problematic pathogens. Many bacteriocins act only on a narrow range of targets and are active at very low (nanomolar) concentrations. For example, we found that thuricin CD specifically eliminates Clostridium difficile bacteria from among the trillions of bacteria in a model gut system (M. C. Rea et al. Proc. Natl Acad. Sci. USA 108, S4639-S4644; 2011). Diarrhoea associated with $C$. difficile infection is an often-fatal disease resulting from the growth of antibiotic-resistant spores after disruption of the gut microbiota by antibiotics.

Researchers are beginning to identify microbes and human microbial populations that are associated with conditions as wide-ranging as liver, coeliac and inflammatory bowel diseases, obesity, diabetes, irritable bowel syndrome, colon cancer, pouchitis and even mental health. We believe that bacteriocins could be used in the future to design and shape 'healthy' bacterial communities. Paul D. Cotter, R. Paul Ross Teagasc Food Research Centre and Alimentary Pharmabiotic Centre, Cork, Ireland. paul.cotter@teagasc.ie Colin Hill Alimentary Pharmabiotic Centre, Cork, and University College Cork, Ireland. Competing financial interests declared. See go.nature.com/lb1n8e.

\section{Flagging flora: heart disease link}

Martin Blaser highlights the connection between the human intestinal microbiota and diabetes, obesity and inflammatory diseases (Nature 476, 393-394; 2011). Another link is the metabolism by the gut flora of the dietary lipid phosphatidylcholine to produce molecules such as trimethylamine $\mathrm{N}$-oxide, which can predict cardiovascular disease (Z. Wang et al. Nature 472, 57-63; 2011).

The surge in heart disease and diabetes started to emerge around the time of the Second World War, when the use of antibiotics first became widespread. Although the causes of this surge are likely to be multifactorial, it is important that we study and preserve our own internal biodiversity.

Sean Davidson Hatter

Cardiovascular Institute, University College London, UK. s.davidson@ucl.ac.uk

CONTRIBUTIONS

Correspondence may be sent to correspondence@ nature.com after consulting the author guidelines at go.nature.com/cmchno. Readers are also welcome to comment online: www.nature.com/nature. 